\title{
Primary Failure of Eruption (PFE) and ankylosis of permanent molars: the surgeon's experience
}

D. Deffrennes ${ }^{1}$, J. Cohen-Lévy²

1 Plastic and maxillofacial surgeon (MD), in private practice, 2, Rue Saint-Pétersbourg, 75008 Paris, France; Hospital practitioner, Department of Plastic and Esthetic Surgery, Lariboisière Hospital, Paris, France

2 Dentofacial orthopedics specialist, former University Hospital Consultant (Paris 7 University), DDS, MS Orthod, PhD, Private practice, Paris, France

\begin{abstract}
Eruption abnormalities involving permanent molars are clinically rare and can be particularly challenging to treat. When there is an obstacle in the eruption pathway, these teeth can be successfully set in the arch most of the time, once the obstacle is cleared. On the other hand, teeth afflicted with ankylosis or Primary Failure of Eruption (PFE) cannot be orthodontically displaced.

PFE has a genetic origin and leads to open bite that can be severe, in relation to a reduced alveolar height. PFE is often also associated with class III malocclusion and dental agenesis, which makes the treatment plan even more complicated.

This article first describes the characteristics of PFE and ankylosis and then presents our own experience, through several clinical cases. One case illustrates and discusses the limits of orthodontics in managing molars showing PFE, despite alveolar corticotomies and bone anchorage devices. Two other clinical cases describe global rehabilitation by osteotomy, bone graft and extensive prosthetic replacement.
\end{abstract}

\section{KEYWORDS}

Primary Failure of Eruption (PFE), tooth ankylosis, orthodontic failure, orthognathic surgery, segmental osteotomy, bone graft

\section{INTRODUCTION}

Genetic, systemic and local factors may all impair dental eruption, leading to delayed or absent progression of a tooth in the arcade. Apart from the special cases of syndromes with craniofacial components (Down's, cleidocranial dysostosis, cranial stenosis, etc.) and hormonal imbalance impacting bone metabolism (thyroid, parathyroid or pituitary deficiency), differential diagnosis should notably determine whether there is an obstacle blocking the eruption pathway or whether it is the eruption mechanism as such that is implicated.

Imaging examination (panoramic X-ray, and often CT or cone-beam CT) is an essential complement to clinical assessment, 
determining germ orientation, maturation stage, root morphology, desmodontal space and lamina dura integrity, follicular sac morphology and dentine density, especially in the cervical and furcation region, screening for replacement resorption and ankylosis ${ }^{6}$.

For clarity's sake, we first specify the concepts of impaction, ankylosis and eruption failure, using the current international terminology, as the respective treatments are diametrically opposed. We then focus on the treatment of mechanical failure of permanent molar eruption, which typically induces posterior open bite that cannot be resolved orthodontically.

For the management of molar eruption delayed by pathway obstacles, the reader is referred to other articles in the present special edition.

\section{IMPACTED AND RETAINED TEETH AND PRIMARY AND MECHANICAL FAILURE OF ERUPTION: DEFINITIONS AND CLINICAL IMPLICATIONS}

\section{What is a "retained" tooth?}

Adding to the complexity of eruption abnormality, a plethora of terms and descriptions have been used, leading to confusion: primary and secondary retention ${ }^{19,20}$, embedding, impaction. Literal translations from English into French have only made matters worse ${ }^{6}$.

The English term "impaction" refers to tooth progression hindered by an obstacle, sometimes mistakenly called a "mechanical" obstacle. Most such eruption disorders are thus caused by local factors: pathway obstacles such as supernumerary germs, odontomas, cysts or tumors, fracture sequelae or sometimes severely fibrous gum. Intra-alveolar crowding and arcade length deficit come under this heading.

The English term "retention" refers to arrested eruption involving not an obstacle or abnormal germ position, but a dental follicle abnormality. The term is often mistranslated from English into French as "dent retenue" ("retained tooth"), which makes it sound as though the tooth were being "retained" or "retarded" by an obstacle, whereas exactly the opposite is the case. Some authors refer to "primary retention" when onset precedes the emergence of the crown in the arch (in which case the tooth always remains embedded) and "secondary retention" when onset is after emergence through the mucosa ${ }^{14,19,20}$.

Recent publications, notably by Frazier-Bowers et al. ${ }^{7,8}$, refer only to primary failure of eruption (hereafter, PFE), which they distinguish from mechanical failure of eruption (MFE); the latter designates not an eruption pathway obstacle but rather a process of ankylosis.

\section{Mechanical failure of eruption $(M F E)^{18,25}$ or isolated ankylosis}

When fusion between the alveolar bone and the cementum disturbs the intra-alveolar progression of a tooth, while the eruption mechanism 
as such is unimpaired (no follicular abnormality), this is referred to as a "mechanical" failure of eruption. There is an abnormal or absent ligament region. Depending on the size of the defect, it may be possible to break the ankylosis point surgically and mobilize the tooth. Ankylosis may then later recur.

The etiology of MFE is usually traumatic, but sometimes unknown ("idiopathic"). The main feature of MFE is normality of the adjacent, and notably posterior, teeth.

Bilateral MFE is extremely rare.

\section{Primary failure of eruption (PFE) $)^{14,18}$}

PFE is a genetic eruption mechanism disorder in the dental follicle, partially or totally blocking tooth progression. It may involve one or several cuspid sectors, with severity sometimes varying within a given individual. First described by Proffit and $\mathrm{Vig}^{18}$, prevalence is $0.06 \%$, with a male-to-female sex-ratio of $1: 2.25^{3,9}$. In $90 \%$ of cases, PFE involves the first molar, then in decreasing order of frequency the second molars and premolars, and only very rarely the anterior teeth ${ }^{22}$. The deciduous teeth may be affected.

There is initially no ankylosis, and teeth show normal desmodontal mobility for a certain time, but with unavoidable secondary ankylosis ${ }^{18}$, occurring spontaneously or following attempted orthodontic traction.

Etiology is thought to be genetic; a familial component should be screened for $4,7,8,10$, as the gene coding for parathyroid hormone receptor 1 (PTHR1) has been implicated ${ }^{7,8}$. Some authors recommend genetic testing in the long term in case of diagnostic doubt ${ }^{8}$, although PTHR1 mutation is not systematically found ${ }^{15}$ and diagnosis is purely clinical and radiological. Early differentiation between MFE and PFE may be impossible, in which case failure of eruption is said to be "indeterminate".

Differential diagnosis with respect to posterior lateral open bite is important ${ }^{17}$, the latter being associated with vertical condylar hypertrophy (unilateral open bite on the side of the hypertrophic condyle), lingual dysfunction with lateral interposition and certain trauma sequelae.

The principal characteristics of PFE $\operatorname{are}^{1,3,4,7,8,10,14,18}$

- all teeth distal to the affected tooth are involved;

- posterior open bite is associated, sometimes with "submergence" of crowns;

- affected teeth do not respond to orthodontic treatment.

PFE is often, but not systematically, associated with class III malocclusion, agenesis and/or ankylosis of deciduous molars.

Two types of PFE are distinguished (Frazier-Bowers et al. ${ }^{7,8}$ ):

- type I, undifferentiated: all affected teeth show similar stage of eruption failure, and thus perhaps similar vertical level within the alveolar bone;

- type II, differentiated: distal teeth show somewhat greater, or at least different, potential for progression, without reaching a functional position in the occlusion plane. This may mislead diagnosis, suggesting possible hope for orthodontic intervention. Unfortunately, teeth affected 
by PFE may at best be displaced by a millimeter or two before inevitable ankylosis sets in.

We present two clinical illustrations: Case 1: Thomas $\mathrm{G}$ (managed by Dr A. Pathammavong, orthodontist in SaintGermain-en-Laye, andDrD.Deffrennes, surgeon in Paris, France).

A 12 year-old boy consulted for late delayed eruption of the left maxillary first molar (26). Occlusion was dental class II (Fig. 1a, b, c, d, e); panoramic $X$-ray showed arrested eruption, without obvious cause, as the teeth and especially roots were vertical and no obstacle appeared (Fig. 2). The left mandibular first molar roots showed curvature (dilaceration), of poor prognosis.
After a period of watchfull waiting, the orthodontist attempted traction between 26 and 36, using orthodontic brackets bonded to the partially exposed crowns, but without success (Fig. $3 a, b$ ). The care team were reluctant to accept that the left maxillary second molar too showed ankylosis. The two permanent first molars, 26 and 36, were extracted, with corticotomy of 27 in the same step, and a bone anchorage was fitted to the mandibular arcade (Fig. 4). The result was unchanged, with no movement in 27. Mesial version was imposed on the mandibular second molar, 37, suggesting that it may not be ankylosed, but it is or soon will be affected by PFE, being distal to an affected molar.

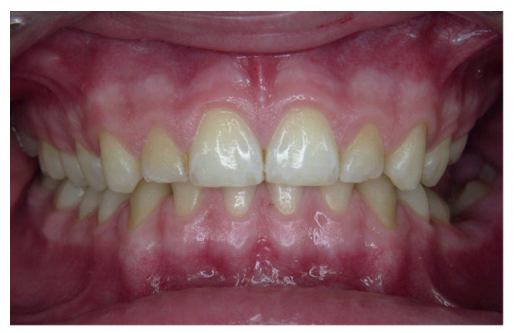

a

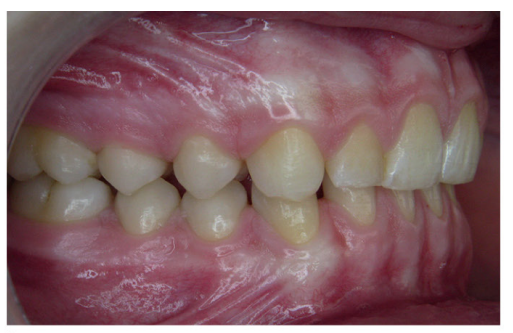

b

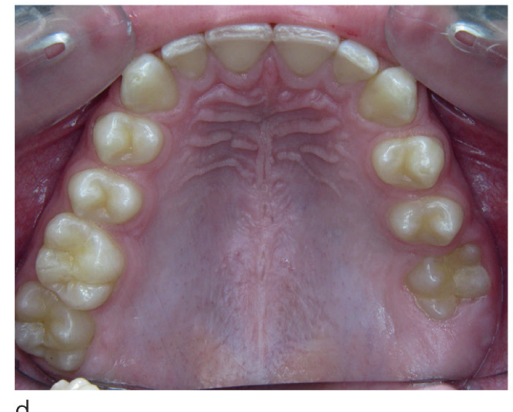

d

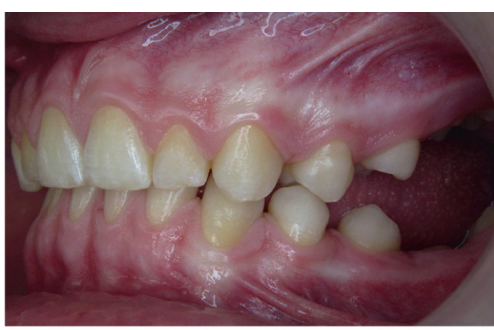

C

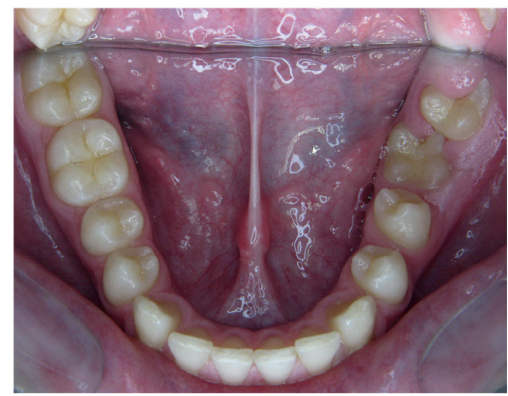

e

Figure 1

Case 1. a) Frontal occlusion view. b) Right occlusion: class II, posterior vertical relations near the lower limit of normal. c) Left occlusion: marked open bite, beginning from premolars. d) Maxillary arcade: only the medial part of 26 is apparent, 27 remaining embedded. e) Mandibular arcade: 36 crown in rotation and marked open bite; 37 is submucosal. 


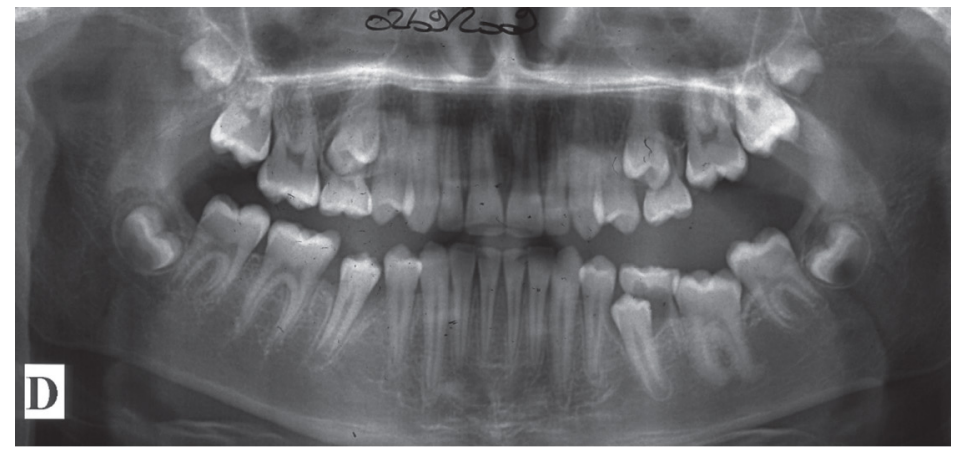

Figure 2

Case 2. Panoramic view. No obstacle in the 26 eruption path; 37 in mesial version, covering part of the occlusal side of 36 .

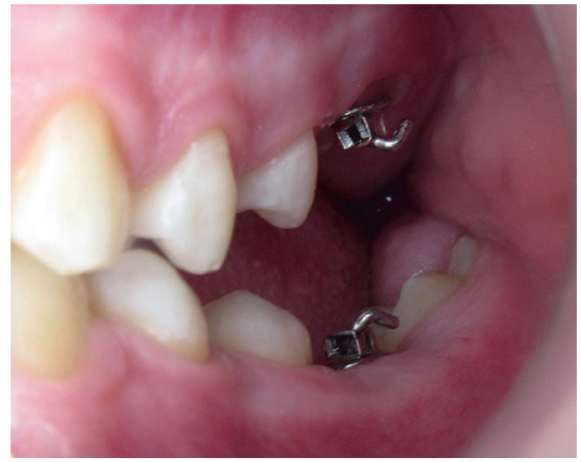

a

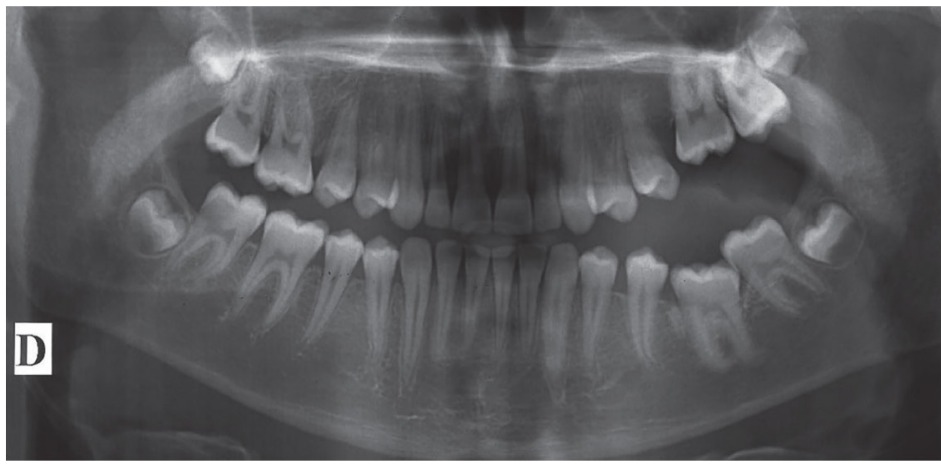

b

Figure 3

a) Despite strong suspicion of PFE, the orthodontist installed elastic traction via brackets between 26 and 37, without success. b) Panoramic control. Situation unchanged for 26 and 36, but with diastema between 25 and 26.27 seems to progress, being at the same level as 26, compared to previous image.

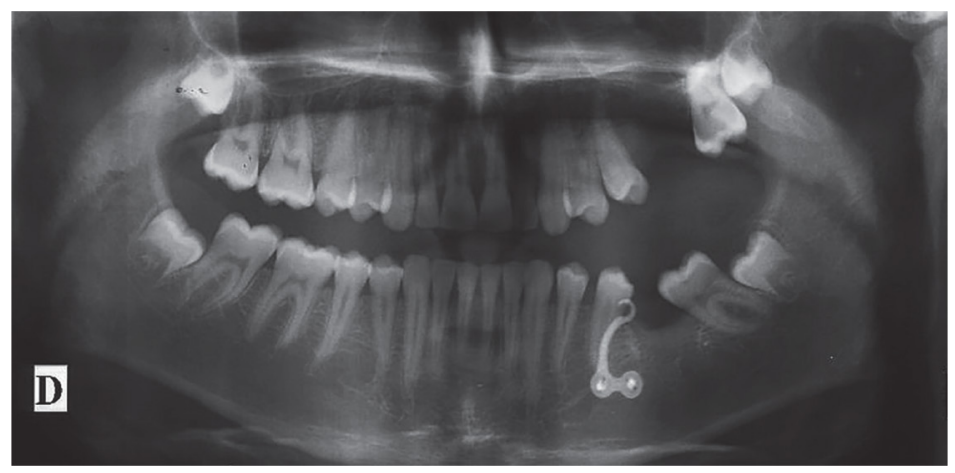

Figure 4

Control view after extraction of 26 and 36 and screwed mandibular arcade anchorage: the second molars, which appeared to show potential progression on the previous image, have not responded to treatment. 
"Partial" corticotomy thus provides no benefit in such cases. Complete segmental osteotomy would have been needed, to mobilize the whole molar sector and allow alveolar distraction. It should be borne in mind that, in this treatment, the crowns remain submucosal, more or less embedded, and that subsequent prosthetic rehabilitation is complicated.

CT found no ankylotic process; dentoalveolar ligament integrity was confirmed, slice by slice, with both mandibular and maxillary reconstruction (Fig. 5a and b, Paris Radiology Institute).

\section{THERAPEUTIC ATTITUDES}

Severity varies greatly in PFE and $M F E$, requiring individualized treatment according to each patient's needs ${ }^{12,27}$.

\section{No intervention (with watchfull waiting) in orthodontics}

The limits of orthodontic treatment have been pushed back, with the advent of bone anchorage and corticocision and corticotomy, and no orthodontic intervention may seem like giving up. It is, however, the only attitude possible in PFE.

- Inchildrenandadolescents with PFE during their active growth phase, facial development, and mastication force in particular, should nevertheless be accompanied.
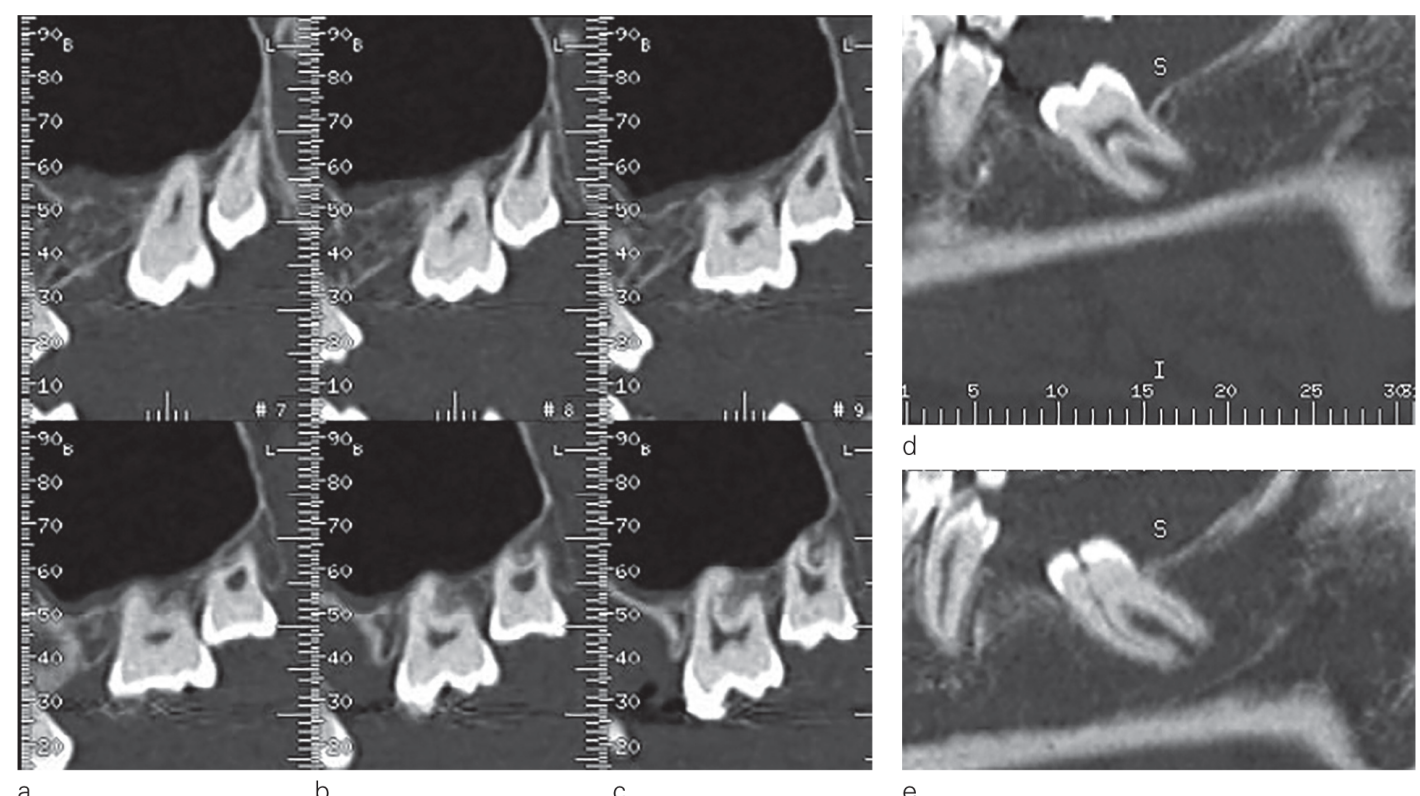

d

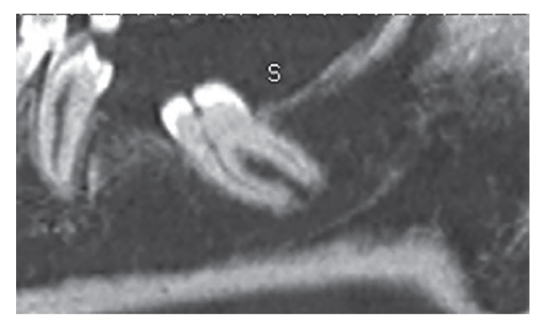

e

Figure 5

Maxillary $(a, b, c)$ and mandibular curvilinear reconstruction $\left(d\right.$, e) by DentaScan ${ }^{(T M)}$ software: root curve in 26, close to sinus, and 36, close to mandibular canal. Periodontal ligament visible on all slices. 
Severe posterior open bite may develop, especially if an anterior tooth is involved (as all the more distal teeth will inevitably be affected) and if ankylosis sets in early, locally arresting alveolar growth.

Leaving the situation as it is risks mastication developing using the anterior teeth, leading to early wear and lateral lingual interposition. Various publications ${ }^{2,12,13,14,24}$ recommend correcting the lateral open bite by a removable prosthesis, to restore posterior occlusion and maintain the vertical occlusion dimension. The prosthesis should be readjusted according to growth, so as not to hinder maxillary expansion. This is a temporary solution, awaiting rehabilitation at the end of the growth phase.

- In isolated ankylosis (MFE), treatment is feasible, and abstention risks allowing migration of adjacent teeth.

\section{Fixed prosthesis rehabilitation}

Fixed prosthetic rehabilitation (onlay) is possible for open bite $<5 \mathrm{~mm}$, at end of growth.

In isolated ankylosis, prostheses may be preceded by orthodontic preparation to correct adjacent version and antagonist compensatory extrusion.

In PFE, on the other hand, all teeth posterior to the affected tooth are inevitably ankylosed and it should not be attempted to mobilize them.

Patients should be informed of the likelihood of recurrence of open bite and the need to revise prostheses following alveolar growth.

\section{Surgical luxation (ankylosis point rupture) followed by orthodontic traction or intentional reimplantation}

Both surgical luxation and reimplantation require optimally conserved root morphology and vascular supply. There is a risk of dental or bone fracture, and they are not recommended in PFE.

Very good results were reported in isolated ankylosis (MFE) ${ }^{16,25}$, although the risk of recurrence of ankylosis remains.

When surgical luxation is to be followed by orthodontic traction, this should be immediate. The force applied to the luxated tooth should be relatively strong and continuous, to prevent early ankylosis. Solid anchorage is needed to offset the strong forces inevitably generated by the mechanical system: various successful cases have been reported with anchorage on osseointegrated orthodontic implant, miniscrew or anchor plate $^{23}$.

\section{Segmental osteotomy followed by vertical fragment repositioning, with or without bone graft}

Segmental osteotomy and displacement may be indicated at end of growth in moderate vertical defect. Severe open bite is not a good indication, as soft tissue stretching is likely to be impossible, jeopardizing healing, with a risk of non-union, periodontal defect and pulpar necrosis.

Segmental osteotomy was successfully implemented by Radolski et al. ${ }^{21}$ to set ankylosed molars, in 
a 2-step procedure followed by fine multibracket adjustment ${ }^{11}$.

\section{Segmental osteotomy with alveolar distraction}

Distraction is an alternative, providing vertical bone tissue and mucosal expansion and improved vascular supply.

There are, however, anatomical obstacles: maxillary sinus (in high, protruding molars) and the mandibular canal, contraindicating the procedure.

In a case report of alveolar distraction in PFE involving a whole quadrant in an adult patient ${ }^{26}$, a $7 \mathrm{~mm}$ vertical defect (as measured at the premolars) was corrected, without bone graft, awaiting prosthetic rehabilitation. The brackets guided the distraction vector, not to displace the individual teeth but to distract the bone mass.

\section{Extraction of molars affected by PFE or ankylosis, ahead of bone graft and implant-borne rehabilitation}

However radical, extraction is mandatory in severe cases. Even so, it may be difficult (dilacerated roots, deep location with risk of creating

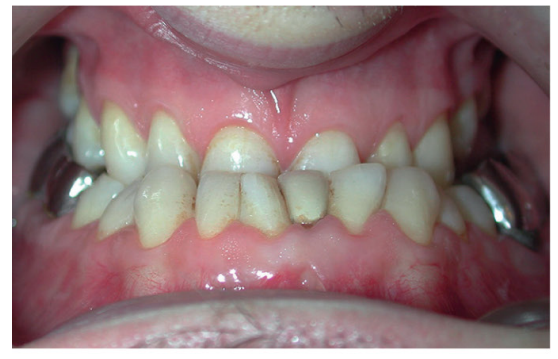

a

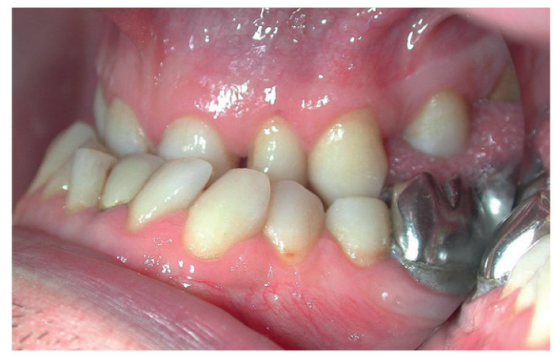

b

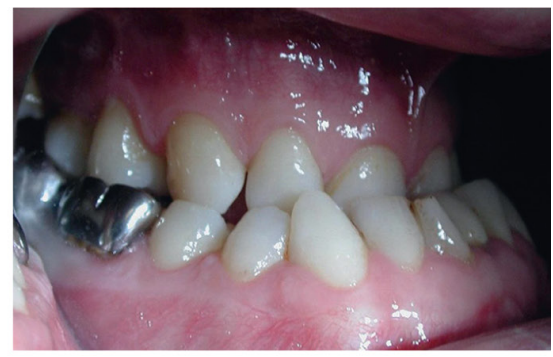

C

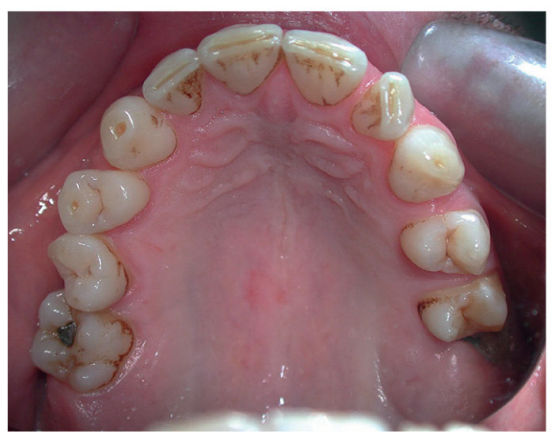

d

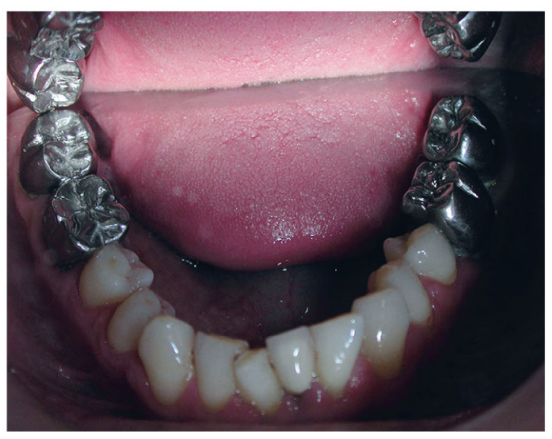

e

Figure 6

Case 2. a) Frontal occlusion view: total inversion of dental relations, from ;premolar to premolar; 31 is crowned. b) Right occlusion view: severe class III, complete posterior lingual occlusion, and open bite beginning at 16. c) Right occlusion view: severe open bite, beginning at maxillary premolars; metal crowns on 36 and 37 show egression.

d) Maxillary arcade: only the mesial part of 26 is visible, 16 shows exposed crown but severe open bite; 15 and 14 severely rotated. 27, 28, 17 and 18 remain embedded. e) Mandibular arcade. 
oral-sinus communication ${ }^{5}$ or inferior alveolar nerve lesion), and bone graft integration is not guaranteed, given the size of the alveolar defect.

Case2:DavidE. (PatientofDrJ.CohenLévy, orthodontist in Paris, and
Dr D. Deffrennes, surgeon in Paris).

A 37 year-old male presented with dental and skeletal class III, hypodivergent skeletal pattern, maxillary retrusion and transverse insufficiency (Fig. 6a, b, c, d, e). Maxillary molar PFE

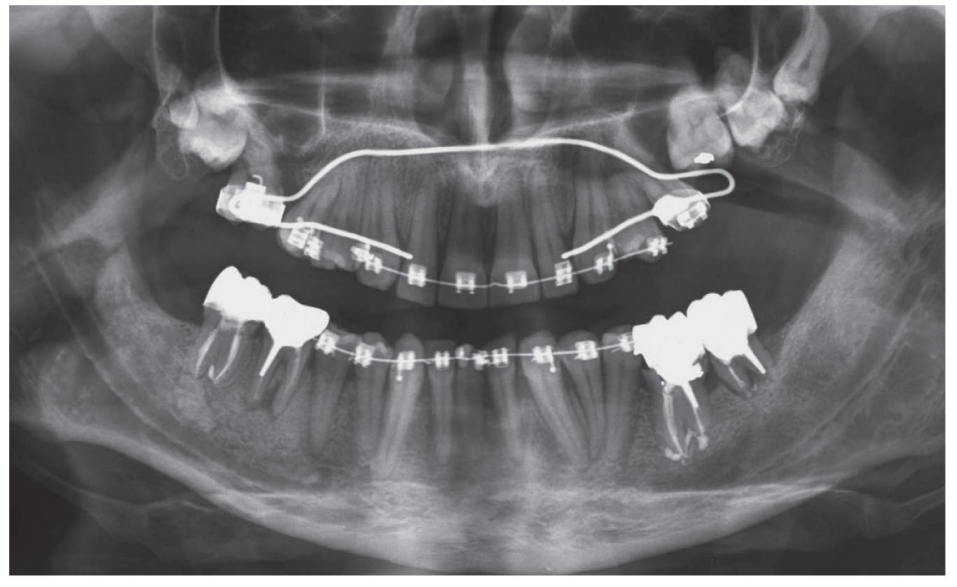

a

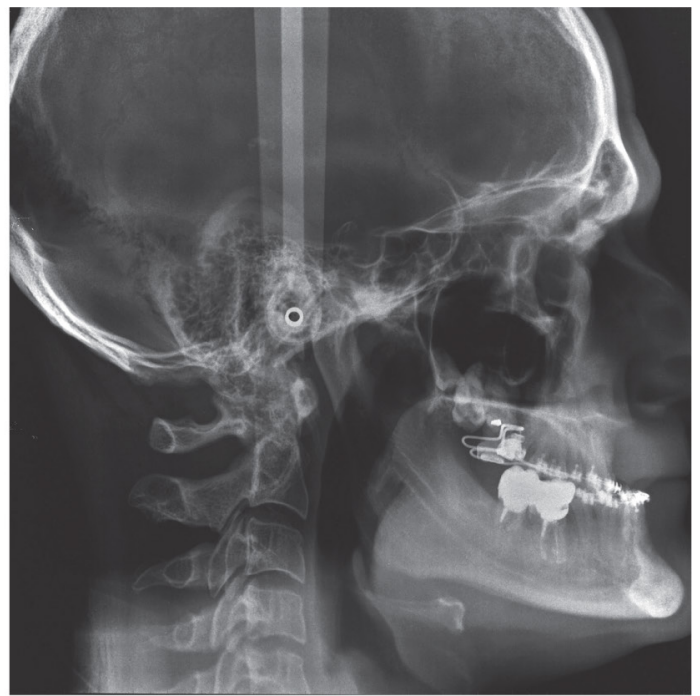

b

Figure 7

Case 2. a) Preoperative panoramic control. Apical lesions on 37 and 46. Dilacerated 17, 26 and 27 roots. 18 hypoplastic. b) Lateral teleradiograph. Note maxillary molar protrusion and size of maxillary defect. The soft tissues are very thick.

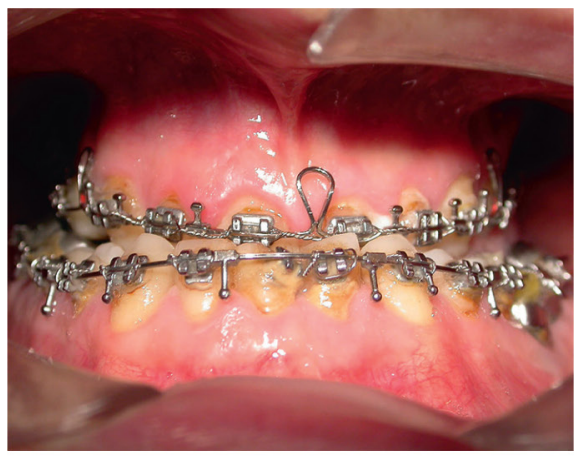

a

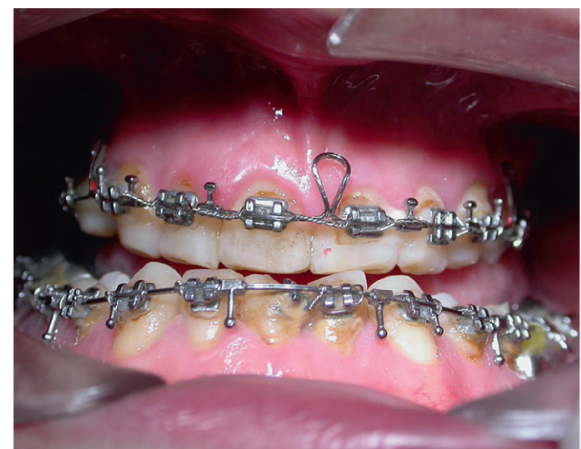

b

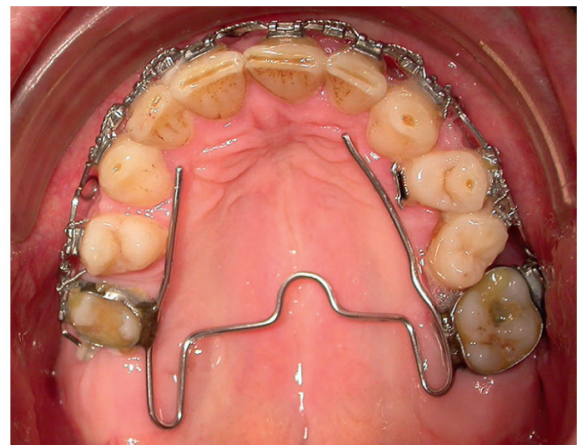

C

Figure 8

a) Frontal occlusion view, mouth closed: surgical arches. b) Frontal occlusion view, mouth open: surgical archwires. c) Maxillary occlusal view transpalatal arch with expansion loops for surgical disjunction. No transverse distraction was performed, due to the slowness of dental displacement and the impossibility of correcting rotation in the premolars, with suspicion of PFE. 


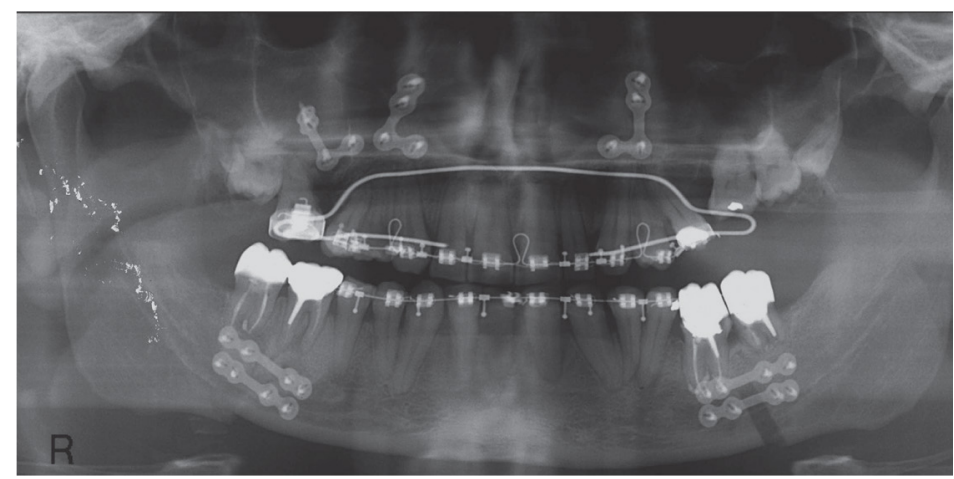

Figure 8

d) Postoperative panoramic view.

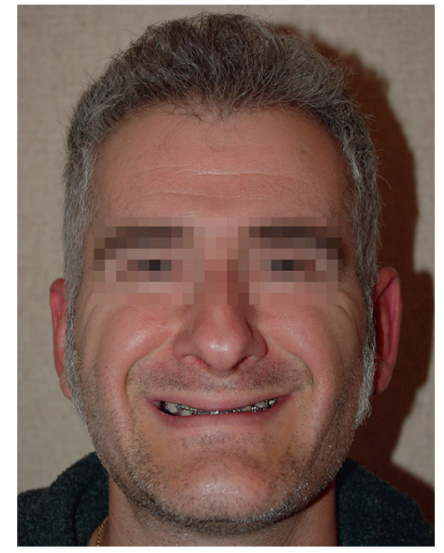

a

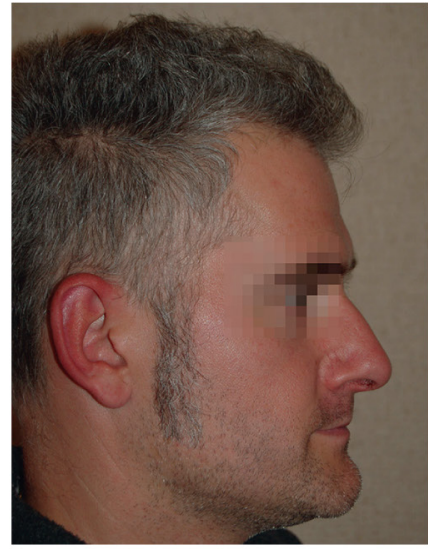

b

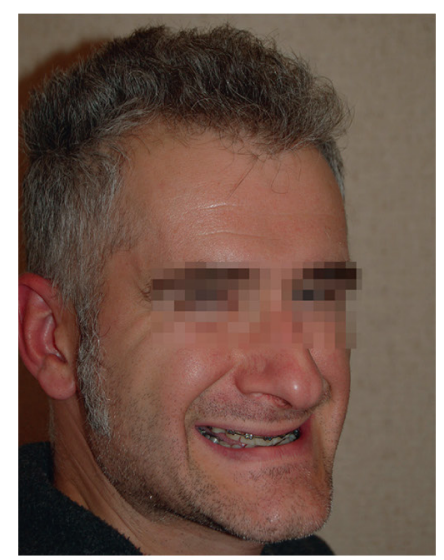

C

Figure 9

a) Preoperative frontal smile view. b) Preoperative lateral view. c) Preoperative smile.

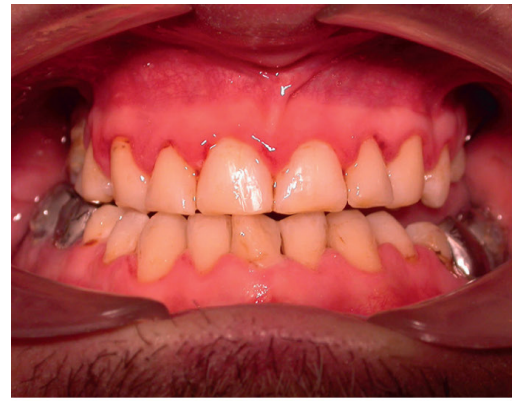

a

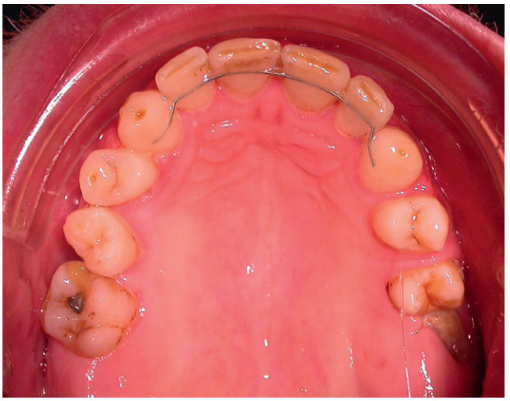

b

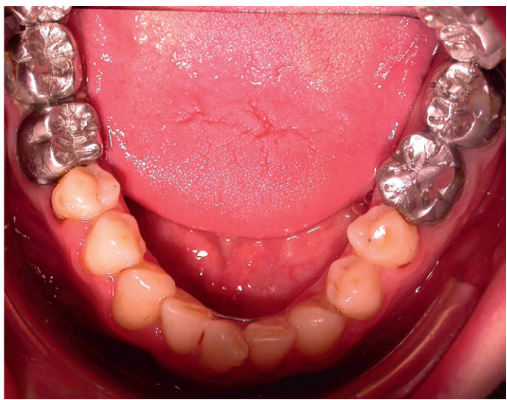

c

Figure 10

a) Frontal occlusion view after bracket ablation. b) Maxillary occlusal view. c) Mandibular view (42 ankylosed). 
involved both quadrants, inducing severe posterior open bite with total submergence of the second and third molars, and distal version and relative ingression of the premolars with diastema. The right first molar had been extracted in childhood. The mandibular molars were non-functional, with previous repair, root resorption and endodontal lesions (Fig. 7a).

Correction of malocclusion was hindered by the skeletal imbalance (Fig. 7b, lateral teleradiograph), with severe anterior lingual occlusion and supra-occlusion and possible physiological disorder of the desmodontal

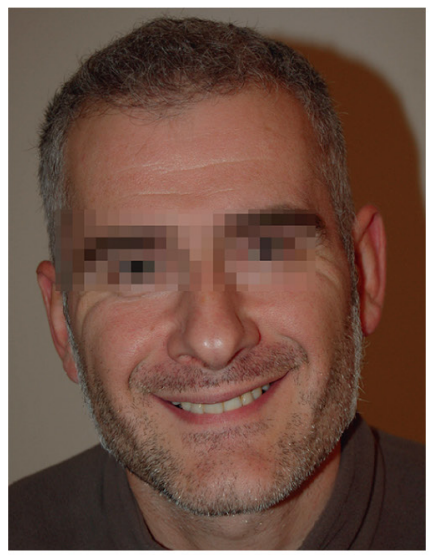

a

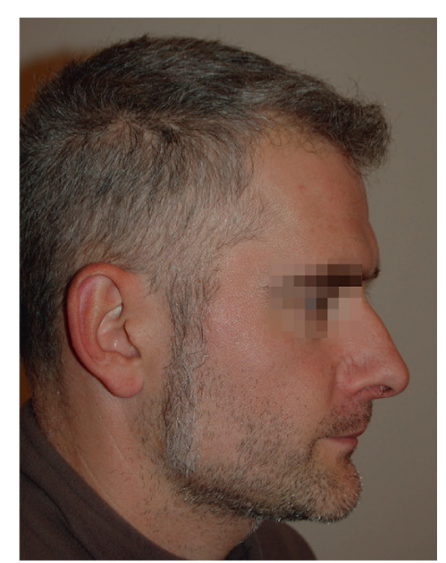

b

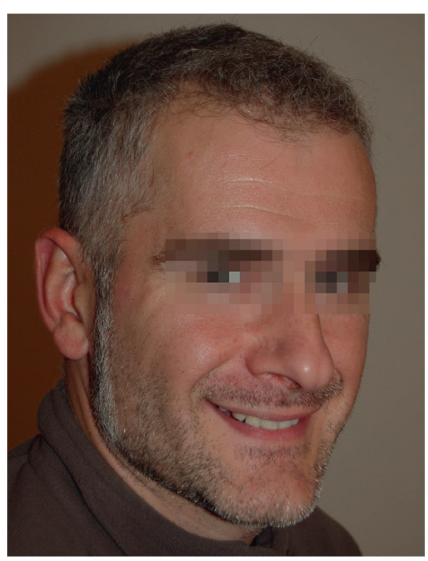

$\mathrm{C}$

Figure 11

a) Postoperative frontal smiling view. b) Postoperative lateral view. c) Postoperative $3 / 4$ smiling view.

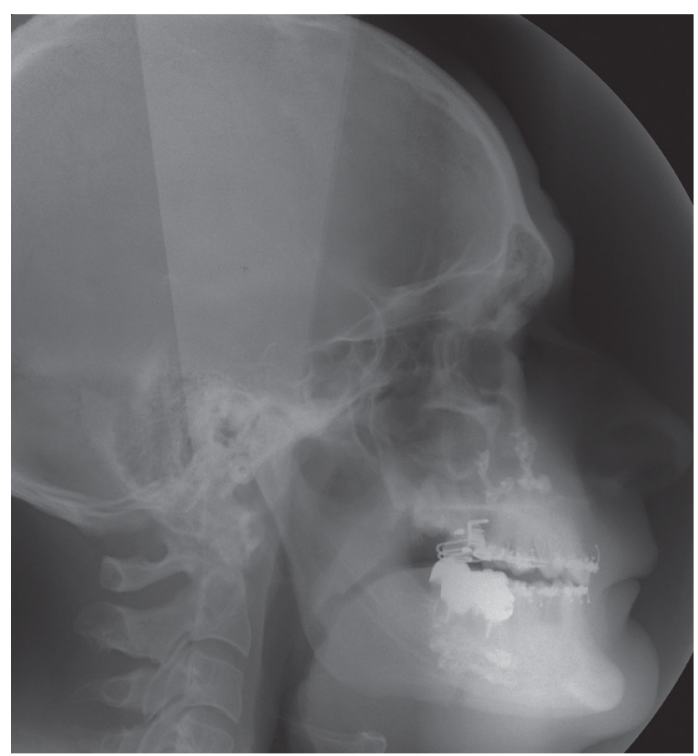

Figure 12

Postoperative lateral teleradiograph.

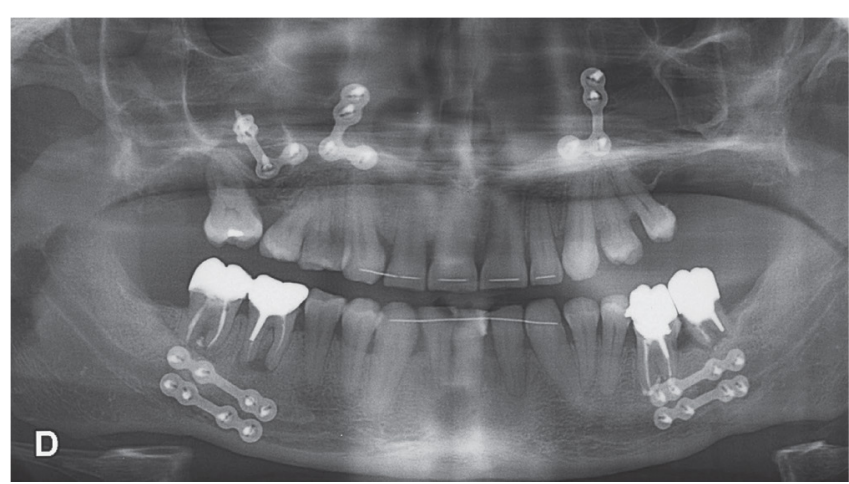

Figure 13

Panoramic control view at 2 years, with 17, 18, 27 and 28 extracted. 
ligament, making displacement very slow. Moreover, during treatment, 42 began to show signs of ankylosis (trauma sequela: 42 had been depulped, crowned then extracted). Orthodontic preparation did not include the ankylosed teeth, to avoid anterior arcade ascension (Fig. 8a, b, $c, d)$.

Le Fort maxillary advancement osteotomy was associated to surgical disjunction (arch with loops and transpalatal arch fitted the day before surgery) and asymmetric lowering, completed by mandibular setback to restore dental class I (Fig. 9 a, b, c preoperative views and Fig. 10a, b, c postoperative intra-oral views).

To restore dental contact, segmental osteotomy of the bone fragment including 26, 27 and 28 was considered during the Le Fort osteotomy,

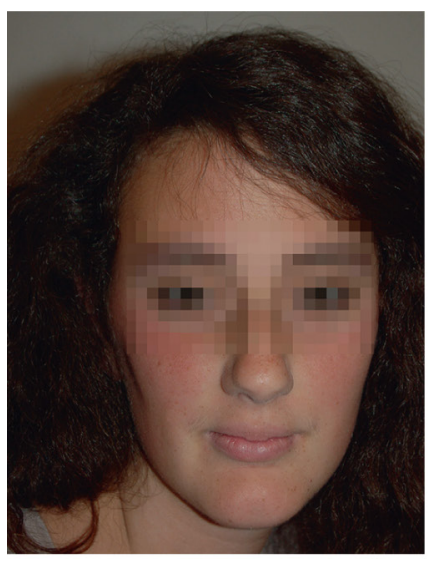

a

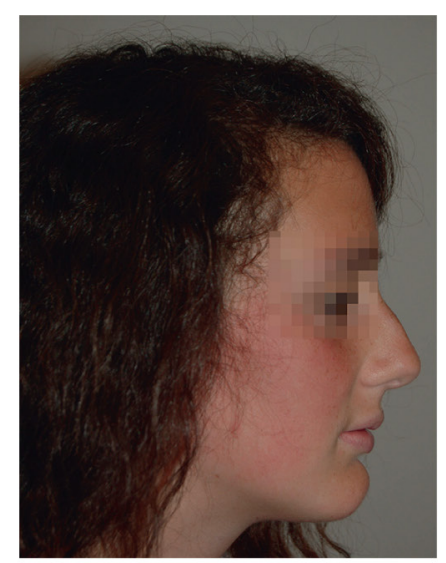

b

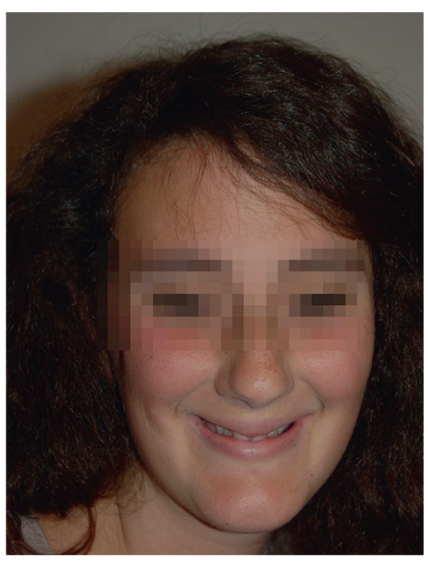

C

Figure 14

Case 3. a) Frontal view, mouth closed. b) Lateral view of skin. c) Frontal smile, severely impaired.
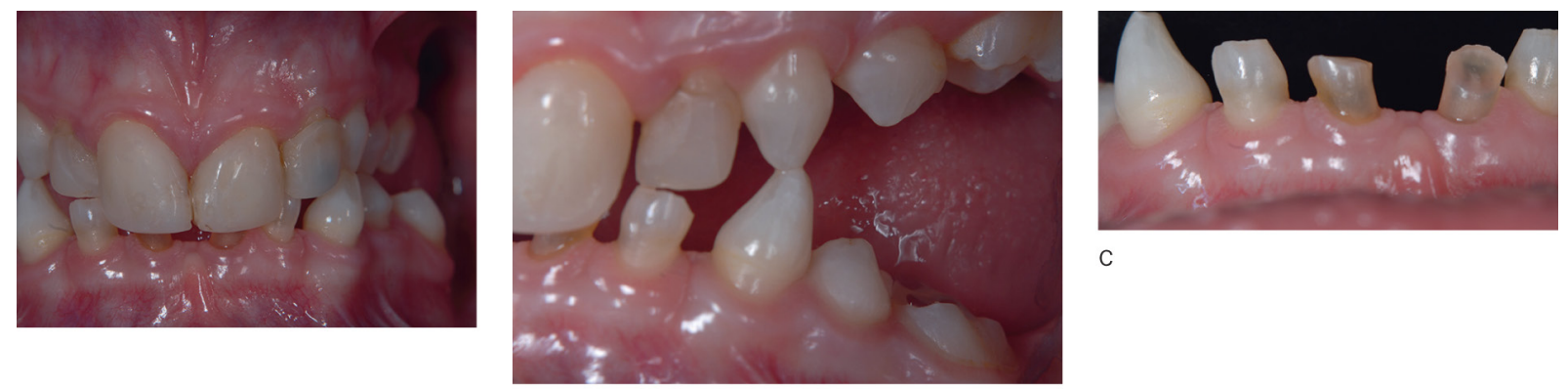

C

Figure 15

a) Frontal occlusion view: severe anterior supra-occlusion and bilateral open bite, especially on right; permanent tooth ageneses with persistent deciduous teeth, only 11 and 21 progressing. b) Class II sagittal relations, severe open bite with lateral lingual interposition. c) Extreme wear in anterior deciduous teeth, bearing all masticatory force. 


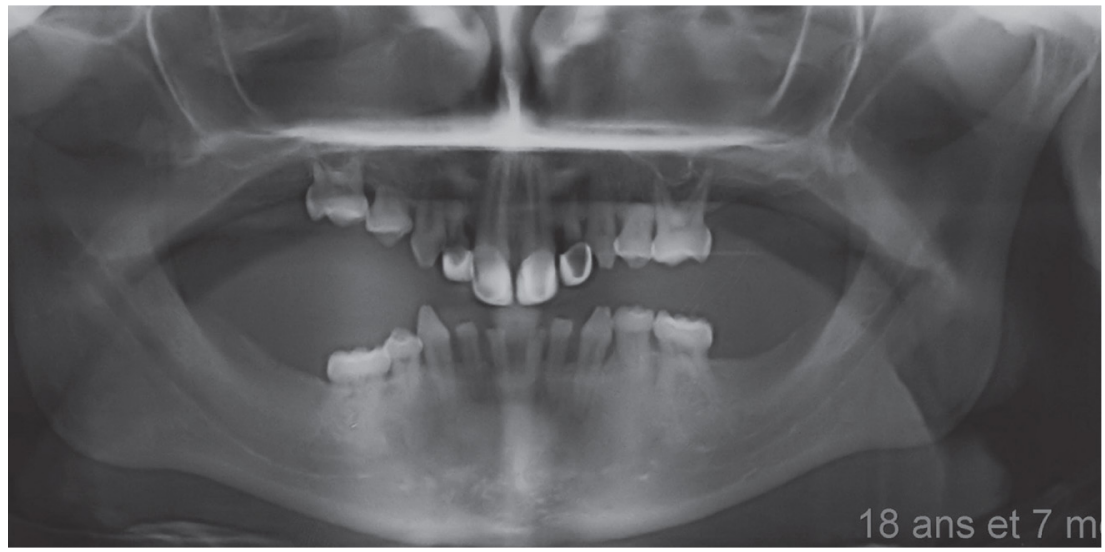

Figure 16

Panoramic radiograph: agenesis of all permanent teeth except 11 and 21, with deciduous molar PFE, typical open bite and alveolar defect

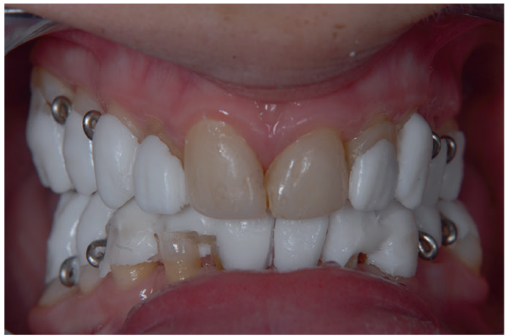

a

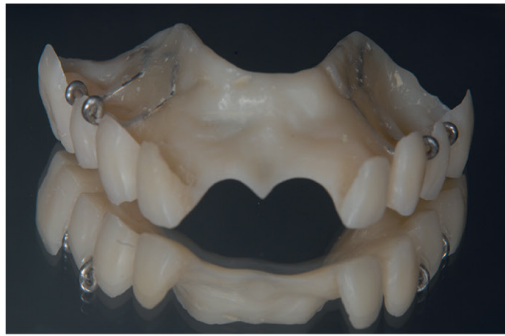

b

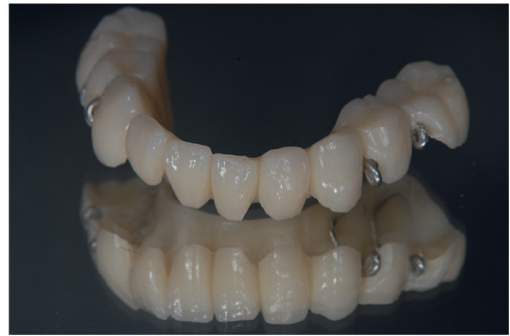

C

Figure 17

a) Presurgical prostheses. b) Provisional maxillary prosthesis with fixation rings. c) Provisional mandibular prosthesis with fixation rings.

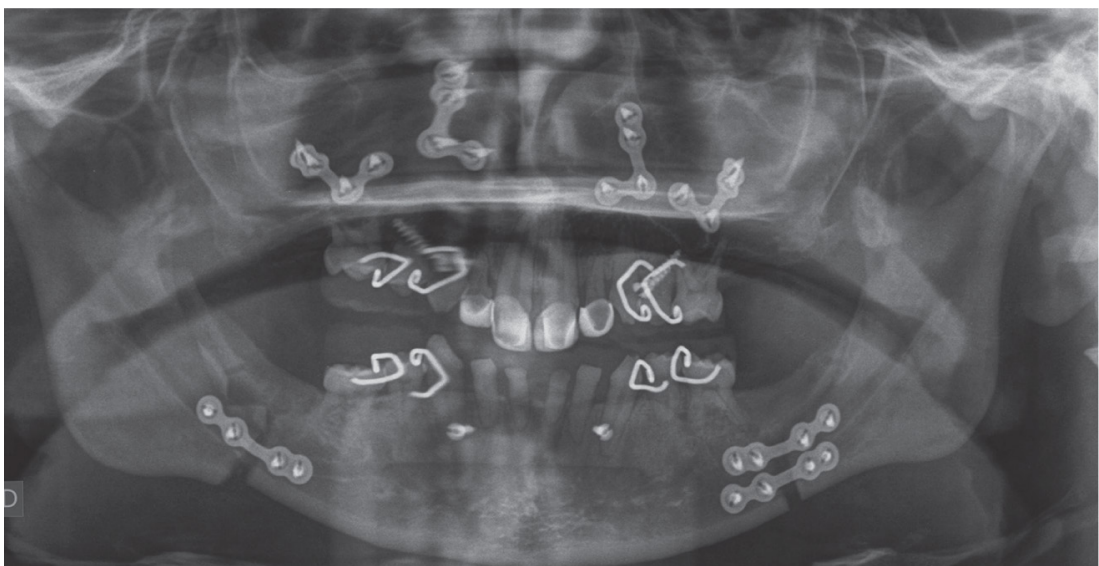

Figure 18

Postoperative panoramic radiograph (osteosynthesis plate position and assessment of implant options). 
but would have incurred too great a risk of non-union, as the multiple osteotomies and low alveolar height would have resulted in poor fragment vascularization. It was decided to perform only orthognathic surgery (Fig. 11a, b, c, Fig. 12), with subsequent molar extraction (Fig. 13) then autologous bone graft before fitting implants and prosthesis.

Unfortunately, the public health system did not cover this treatment; moreover, the upcoming procedures were going to be heavy, and the patient no longer wanted to continue, being already very pleased with the esthetic result. He had been informed of the poor prognosis for the inferior molars and the risk of infection, requiring extraction - but was not convinced.

Case 3: Camille N. (patient of Dr P. Zyman, prosthetist in Paris, M. Davarpanah, implantologist in

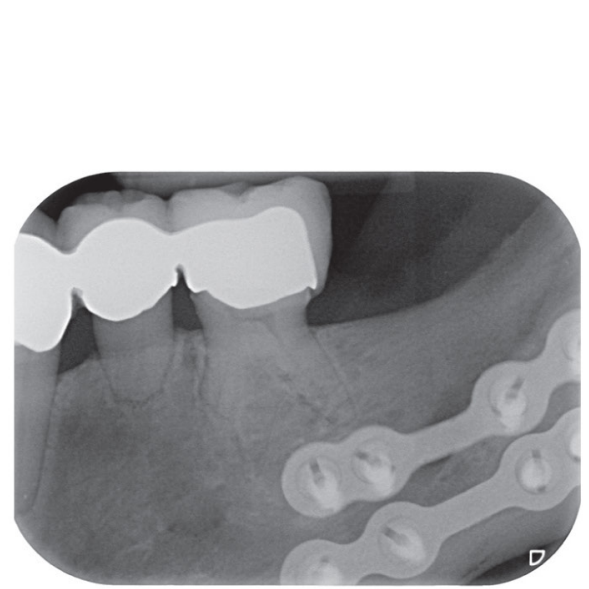

a

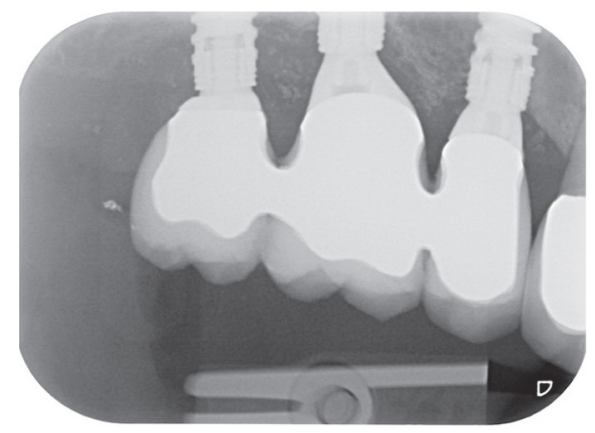

d

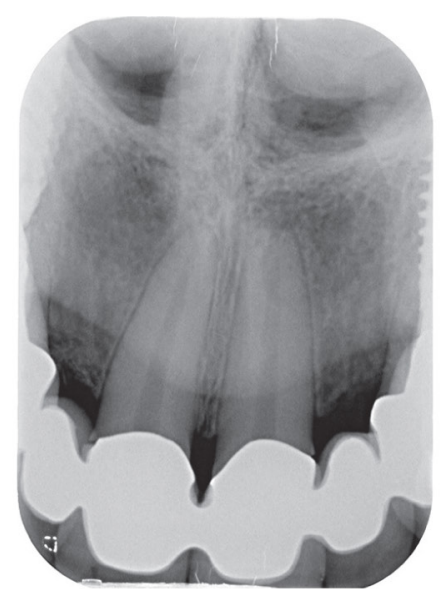

b

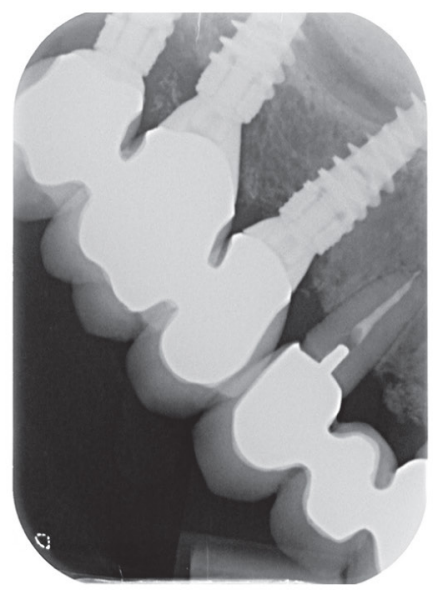

e

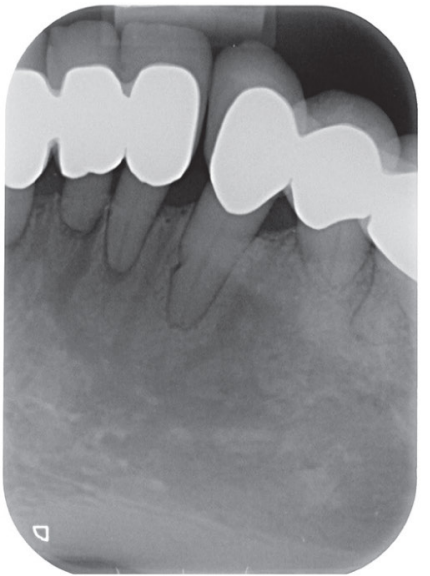

C

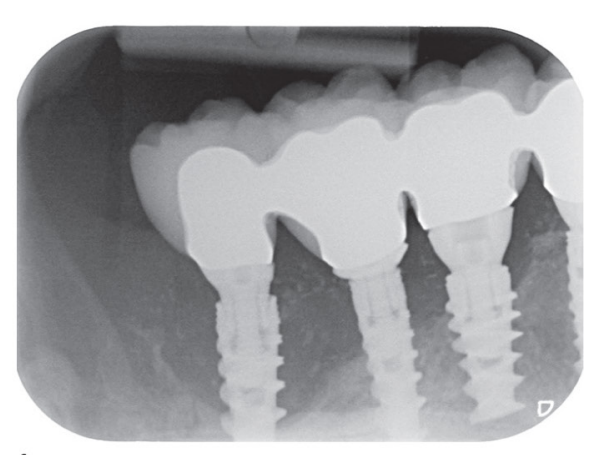

f

Figure 19

a) Prostheses on temporary molars. b) Bridge supported by maxillary incisors, c) and mandibular incisors. d) Implant-borne bridge (note low bone density), not fused to natural teeth. e) Implant-borne bridge (other sector ). f) Other sector. 

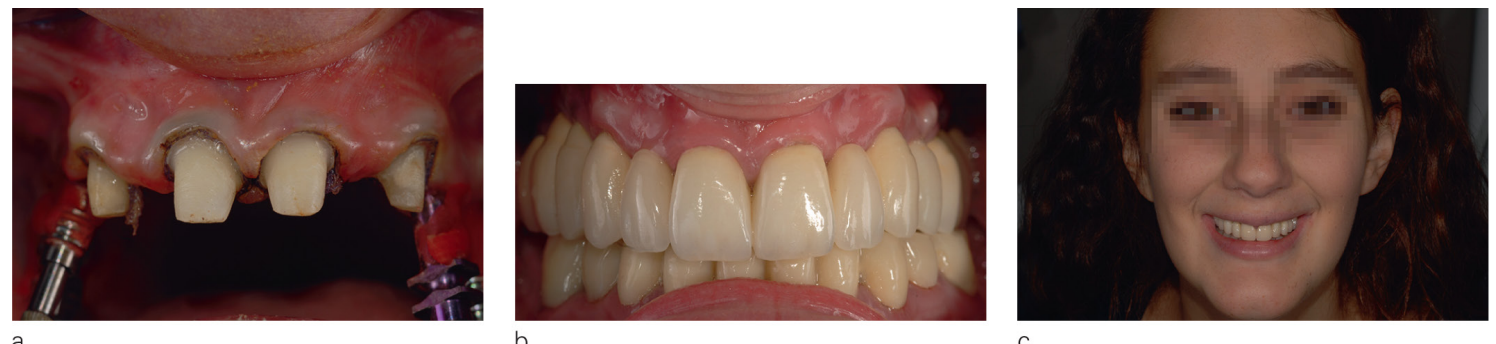

Figure 20

a) Dental preparations and implant transfer. b) Provisional prostheses. c) Temporary result (smile view).

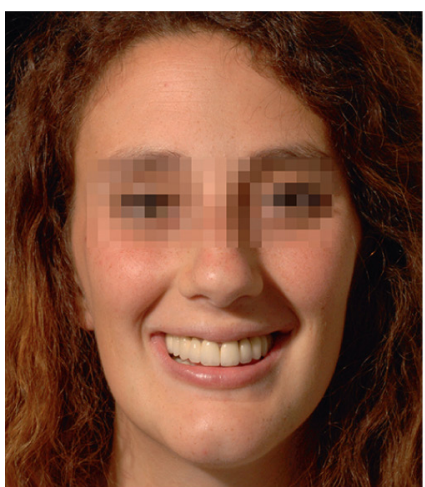

a

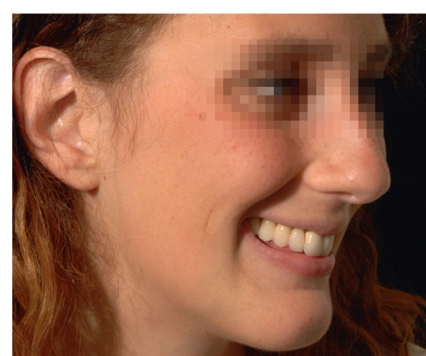

b

Figure 21

a) Frontal smile view. b) 3/4 smile view.

Paris, and Dr D. Deffrennes, surgeon in Paris).

This 18 year-old patient presented with multiple ageneses, micromaxilla and bilateral open bite due to PFE involving all 4 quadrants. She reported difficulty chewing, over and above the esthetic issue. Smiling was impaired (Fig. 14a, b, c).

There was anterior supra-occlusion with severe bilateral open bite (Fig. 15a, b, c, Fig. 16), precluding straightforward posterior prosthetic rehabilitation. A program of extractions and bone grafts ahead of implant-borne prostheses was discussed; but, in view of the deficient receiver-site area, jeopardizing healing, an alternative was sought.

The option chosen was:

- Maxillomandibular orthognathic surgery to reduce lateral open bite and restore a harmonious smile. The dentist produced a provisional model: a temporary prosthesis providing the surgeon with reliable occlusion landmarks for the postsurgical result. Two prostheses were needed (fig. 17a, b, c). The surgeon fixed them at the start of sur- 
gery, before performing osteotomy. Surgery created a favorable situation for producing the implantborne prostheses (Fig. 18), and the smile and skin on lateral view were much improved.

- Increased bone volume, both by filling the inferior part of the maxillary sinuses and by appositional bone graft (right parietal cranial harvesting.
- Implantation after healing. The appositional bone grafts were partially resorbed at this point, requiring new membrane-stabilized grafts (Fig. 19).

- Rehabilitation by fixed prosthesis. Temporary results (Fig. 20a, b, c) and result with definitive implantborne bridge are shown (Fig. 21a, b: note low bone density).

\section{CONCLUSION}

Primary failure of eruption (PFE) is systematically associated with open bite and reduced alveolar height at the affected teeth. Open bite may extend to the premolars, be maintained by lingual interposition (even if this is not the original cause) and is more severe when onset is early. In isolated ankylosis (MFE), the defect is limited, although the tooth may be positioned deeply.

Treatment is both heavy for the patient and complex for the team, comprising one or several surgical steps before fitting the prosthesis, following an individualized program at end of growth. The teeth cannot and should not be treated orthodontically, which would make the program even heavier for the patient and moreover worsen the situation, especially if continuous arches were to be used.

Our treatment protocol requires initial surgical correction of bone base discrepancy, often preceded by orthodontic preparation, which does not include ankylosed teeth or those affected by the PFE. Only after coronary elongation or implantation (often preceded by bone graft, in view of the vertical alveolar defect) can occlusion be rehabilitated.

\section{Conflict of interest}

The authors declare no conflicts of interest.

\section{REFERENCES}

1. Ahmad S, Bister D, Cobourne MT. The clinical features and aetiological basis of primary eruption failure. Eur J Orthod 2006;28(6):535-540.

2. Atobe M, Sekiya T, Tamura K, Hamada Y, Nakamura Y. Severe lateral open bite caused by multiple ankylosed teeth: a case report. Oral Surg Oral Med Oral Pathol Oral Radiol Endod 2009;107(4):e14-20.

3. Baccetti T. Tooth anomalies associated with failure of eruption of first and second permanent molars. Am J Orthod Dentofacial Orthop 2000;118(6):608-610.

4. Brady J. Familial primary failure of eruption of permanent teeth. J Orthod 1990;17(2):109-113. 
5. Chaushu S, Becker A, Chausu G. Orthosurgical treat- ment with lingual orthodontics of an infraoccluded maxillary first molar in an adult. Am J Orthod Dentofacial Orthop 2004;125:379-387.

6. Cohen-Lévy J, Cohen N. Anomalies d'éruption des molaires permanentes: diagnostic différentiel et explorations radiographiques. Rev Orthop Dentofaciale 2015;49(3):217230.

7. Frazier-Bowers SA, Simmons D, Wright JT, Proffit WR, Ackerman JL. Primary failure of eruption and PTH1R: The importance of a genetic diagnosis for orthodontic treatment planning. Am J Orthod Dentofacial Orthop 2010;137(2):160-e1.

8. Frazier-Bowers SA, Koehler KE, Ackerman JL, Proffit WR. Primary failure of eruption: further char- acterization of a rare eruption disorder. Am J Orthod Dentofacial Orthop 2007; 131(5),578-e1.

9. Grover PS, Lorton L. The incidence of unrupted per- manent teeth and related clinical cases. Oral Surg Oral Med Oral Pathol 1985;59:420-425.

10. Ireland AJ. Familial posterior open bite: a primary failure of eruption. J Orthod 1991;18(3):233-237.

11. Kang YG, Kim JY, Lee YJ, Lee BS. Segmental repo- sitioning combined with orthodontic fine adjustment of nonerupting permanent molars: a case report. Quintessence Int 2010;41(6):449-458.

12. Lyczek J, Antoszewska J. Primary failure of eruption. Etiology, Diagnosis and Treatment. Dent Med Probl 2013;50(3):349-354.

13. Mc Cafferty J, Al Awadi E, O'Connell AC. Case report: Management of severe posterior open bite due to primary failure of eruption. Eur Arch Paediatr Dent 2010;11(3):155158.

14. Palma C, Coelho A, González Y, Cahuana A. Failure of eruption of first and second permanent molars. J Clin Ped Dent 2003;27(3):239-245.

15. Pilz P, Meyer-Marcotty P, Eigenthaler M, Roth H, Weber BHF, Stellzig-Eisenhauer A. Differenzialdiagnostik der primären Durchbruchstörung (PFE) mit und ohne Nachweis einer krankheitsassoziierten Mutation im PTHR1-Gen. J Orofacial Orthopedics/ Fortschritte der Kieferorthopadie 2014;75(3):226-239.

16. Pithon MM1, Bernardes LA. Treatment of ankylosis of the mandibular first molar with orthodontic traction immediately after surgical luxation. Am J Orthod Dentofacial Orthop 2011;140(3):396-403.

17. Ponsford MW1, Stella JP. Algorithm for the differen- tial diagnosis of posterior open bites: two illustrative cases. J Oral Maxillofac Surg 2013;71(1):110-27.

18. Proffit WR, Vig KW. Primary failure of eruption: a possible cause of posterior open-bite. Am J Orthod 1981;80(2):173-190.

19. Raghoebar GM, Boering G, Jansen HWB, Vissink A. Secondary retention of permanent molars: a histologic study. J Oral Path Med 1989;18(8):427-431.

20. Raghoebar GM, Boering G, Vissink A, Stegenga B. Eruption disturbances of permanent molars: a review. J Oral Path Med 1991;20(4):159-166.

21. RazdolskyY, El-Bialy TH, Dessner S, Buhler JE Jr. Movement of ankylosed permanent teeth with a distraction device. J Clin Orthod 2004;38(11):612-620.

22. Rhoads GC, Hendricks HM, Fraziers-Bowers SA. Establishing the diagnostic criteria for eruption disorders based on genetic and clinical data. Am J Orthod Dentofacial Orthop 2013;144:194-202.

23. Rosner D, Becker A, Casap N, Chaushu S. Orthosurgical treatment including anchorage from a palatal implant to correct an infraoccluded maxillary first molar in a young adult. Am J Orthod Dentofacial Orthop 2010;138(6):804-809. 
24. Siegel SC, O'Connell A. Oral Rehabilitation of a child with primary failure of eruption. J Prosthodont 1999(8):201-207.

25. Smith CP, Al-Awadhi EA, Garvey MT. An atypical pre- sentation of mechanical failure of eruption of a mandibular permanent molar: diagnosis and treatment case report. Eur Arch Paediatr Dent 2012;13(3):152-156.

26. Susami T, et al. Segmental alveolar distraction for the correction of unilateral open-bite caused by multiple ankylosed teeth: a case report. J Orthod 2006;33(3):153-159.

27. Valmaseda-Castellón E, De-la-Rosa-Gay C, Gay-Escoda C. Eruption disturbances of the first and second permanent molars: results of treatment in 43 cases. Am J Orthod Dentofacial Orthop 1999;116(6):651-658. 